\title{
O ENSINO DE PLANTAS E EDUCAÇÃO AMBIENTAL: ESTRATÉGIAS PARA O ENSINO DE CIÊNCIAS NA AMAZÔNIA
}

Carolina Ferreira Guimarães

Graduada em Educação Especial na Universidade do Estado do Pará. E-mail: carolguimarães1707@gmail.com

\section{Enilene da Conceição Nunes}

\begin{abstract}
Graduada do Curso de Licenciatura Plena em Pedagogia pela Universidade do Estado do Pará. Atualmente trabalha como professora na Escola Municipal de Ensino Fundamental de Cururú, localizada no espaço rural, vinculada a Secretaria de Educação de Salvaterra ( SEMED). E-mail:lenenunes17@gmail.com
\end{abstract}

Sávio Nascimento Rocha

Graduado em Ciências Naturais com habilitação em biologia, pela Universidade do Estado do Pará (UEPA). E-mail: savionascimentorocga@gmail.com

Silvana Ferreira Lima

Graduada em Licenciatura Plena em Pedagogia pela Universidade do Estado do Pará (UEPA). Mestranda em Educação em Ciências e Matemáticas na Universidade Federal do Pará (UFPA). E-mail: silvanaferreira.uepa@gmail.com

\section{RESUMO}

O presente trabalho corresponde a uma prática de Educação Ambiental na Escola Municipal de Ensino Fundamental e Infantil Zacarias Castro de Araújo localizada no município de Salvaterra-PA, tendo como objetivo envolver a comunidade escolar em questões ambientais; sensibilização com a natureza e sobretudo na problemática que envolve o descarte dos resíduos orgânicos e inorgânicos no meio ambiente sem orientação e o estudo das plantas. Nesse contexto, atualmente ainda persiste uma resistência em inserir nas escolas seja em qualquer nível educacional práticas diferenciadas a partir das temáticas transversais, tais como a Educação Ambiental, sobreposta nos Parâmetros Curriculares Nacionais (1997), onde defende que a escola deve ser um espaço de construção de conhecimento sistematizado, valores, cidadania e também para o despertar do cuidado socioambiental. A prática metodológica se deu com o procedimento da compostagem feita pelos alunos e posteriormente, contribuiu para a construção e adubo para horta escolar e o estudo dos vegetais presente na 
horta. O público-alvo foram alunos do $3^{\circ}$ ano do ensino fundamental menor. Constatou-se que pode utilizar a compostagem como ferramenta de educação ambiental no processo de ensino/aprendizagem possibilitando a participação da comunidade escolar na práxis de educação ambiental.

PALAVRAS-CHAVE: Compostagem. Educação Ambiental. Plantas.

\title{
PLANT EDUCATION AND ENVIRONMENTAL EDUCATION: STRATEGIES FOR SCIENCE TEACHING IN THE AMAZON
}

\begin{abstract}
The present work corresponds to an Environmental Education practice at the Municipal School of Elementary and Infant Education Zacarias Castro de Araújo located in the municipality of Salvaterra-PA, aiming to involve the school community in environmental issues; sensitization with nature and above all in the problem that involves the disposal of organic and inorganic residues in the environment without guidance and the study of plants. In this context, currently there is still resistance to insert differentiated practices in schools at any educational level based on transversal themes, such as Environmental Education, superimposed on the National Curriculum Parameters (1997), where he argues that the school should be a space for construction of systematized knowledge, values, citizenship and also for the awakening of socio-environmental care. The methodological practice took place with the composting procedure carried out by the students and subsequently contributed to the construction and fertilizer for the school garden and the study of the vegetables present in the garden. The target audience was students from the 3rd year of minor elementary school. It was found that composting can be used as an environmental education tool in the teaching / learning process, enabling the participation of the school community in environmental education praxis.
\end{abstract}

\section{KEYWORDS: Composting. Environmental Education. Plants.}

\section{INTRODUÇÃO}

Este trabalho corresponde a uma prática de educação ambiental na Escola Municipal de Ensino Fundamental e Infantil Zacarias Castro de Araújo, situado no centro do município de Salvaterra, localizado na Ilha do Marajó, Pará. Desenvolvido com o objetivo de envolver a comunidade escolar nas questões ambientais tais como: o estudo das plantas e sobre tudo na problemática que envolve o descarte dos resíduos orgânicos de forma inadequada. Haja vista que ainda existe um grande desafio de inserir nas escolas práticas escolares sustentáveis a partir dos temas transversais tais como a educação ambiental, aplicada nos Parâmetros Curriculares 
(1997).

No século XXI com o crescimento exacerbado da população e a presença cada vez mais inovadora das tecnologias tornou-se preocupante a destinação dos resíduos originados, pois sabemos que com o crescimento populacional, houve também um aumento na quantidade de resíduos domésticos gerados pelo homem, por conseqüência descartados nos solos, rios, mares... Muitas das vezes contaminando as florestas, deixando o solo infértil e levando sérios problemas ambientais. Como afirma Dias:

No atual contexto de desenvolvimento global, marcado pelo grande avanço tecnológico, aumento na produção e consumo, ocorrendo de forma desigual e a qualquer custo, frequentemente se assiste à degradação ambiental. Essa degradação se reflete na perda da qualidade de vida, destruição de habitats e consequente redução da biodiversidade. (DIAS, 2004)

Percebemos a grande quantidade materiais orgânicos que são descartados aos aterros sanitários sem nenhum tratamento adequado e ou se quer uma separação desses resíduos, além de ser grande desperdício de nutrientes. Devido isso surge a preocupação com o planeta e com a sociedade, trazendo questionamentos e inquietações sobre essa atual e preocupante situação. Diante de isso brotar- se a criação de estratégias que visam o reaproveitamento dos resíduos orgânicos, no processo chamado compostagem. De acordo com D' Almeida, apud Junkes, entende- se por compostagem:

A compostagem é o processo de decomposição biológica da matéria orgânica contida em restos de origem animal ou vegetal, obtendo como resultado final um composto orgânico que pode ser aplicado ao solo, podendo melhorar sua características sem ocasionar riscos ao meio ambiente, (D'ALMEIDA, apud JUNKES 2002).

Percebe-se que a utilização do procedimento da compostagem é de grande importância cooperando para o processo ecológico na relação homem/natureza contribuindo assim para a diminuição de problemas ambientais, além da fertilização do solo, colaborando de tal modo para um ensino/aprendizagem significativo, pois vale salientar os conceitos de sustentabilidade, interdisciplinaridade, ecologia, valores, hábitos saudáveis haja vista que a matéria orgânica após o processo de compostagem servirá de adubos para horta escolar estabelecendo assim uma alimentação saudável e nutritiva.

\section{DESENVOLVIMENTO}


Diante desse contexto este trabalho tem por objetivo desenvolver aos alunos a participação em questões ambientais necessariamente no caso do estudo das plantas e do descarte de lixo orgânico além de utilizar a compostagem como ferramenta de educação ambiental dos discentes da Escola Municipal de Ensino Fundamental e Infantil Zacarias Castro com vistas a promover alternativas para o reaproveitamento do material orgânico, sensibilizando sobre a sustentabilidade, devido isto será utilizado à técnica de construção de minis composteiras com materiais recicláveis.

Este projeto foi realizado com os alunos do $3^{\circ}$ ano matutino e vespertino da Escola Municipal de Ensino Infantil e Fundamental Zacarias Castro de Araújo no município de Salvaterra. O público mencionado possui faixa etária entre 8 a 9 anos entre os sexos masculino e feminino, além disso, a turma apresenta um nível de desenvolvimento eficaz acerca dos assuntos propostos em sala de aula, por isso as práticas do projeto estão de acordo com o perfil dos mesmos. A prática será dividida em quatro momentos:

\section{Primeiro dia:}

$1^{\circ}$ momento: Micro aula objetiva-se indagar os alunos sobre as plantas e a sua relevância para os seres humanos, levando em consideração as espécies da realidade local, foi ressaltado sobre as partes que compõem uma planta, a influência da fertilidade do solo para a plantação e a importância da educação ambiental, levando a refletir sobre a influência das nossas ações para um ambiente sustentável; além de leitura ativa abordando aspectos geográficos de destino dos resíduos no município de Salvaterra e a história do Pet no mundo.

\section{Segundo dia:}

$2^{\circ}$ momento: Montagem de composteiras alternativas de garrafa pet; separação do material orgânico, tais como cascas de vegetais (frutas, legumes e verduras); construção das composteiras com os materiais solicitados. No $1^{\circ}$ passo foi cortar os materiais orgânicos em pequenos pedaços e misturá-los. O $2^{\circ}$ passo consistiu em recortar as garrafas pets ao meio. Em seguida montamos as minis composteiras colocando a parte de cima da garrafa com a boca para baixo da parte inferior. Já no $3^{\circ}$ passo colocamos a areia e em seguida a terra preta na garrafa. No $4^{\circ}$ passo acrescentamos os resíduos orgânicos em pequenos pedaços, a terra preta, as minhocas e a serragem. $5^{\circ}$ passo e tampamos as minis composteiras com a tela e a liga elástica. Após pronta os alunos mediram as suas composteiras. 
FIGURA 1 - Resíduos Orgânicos trazidos pelos alunos.

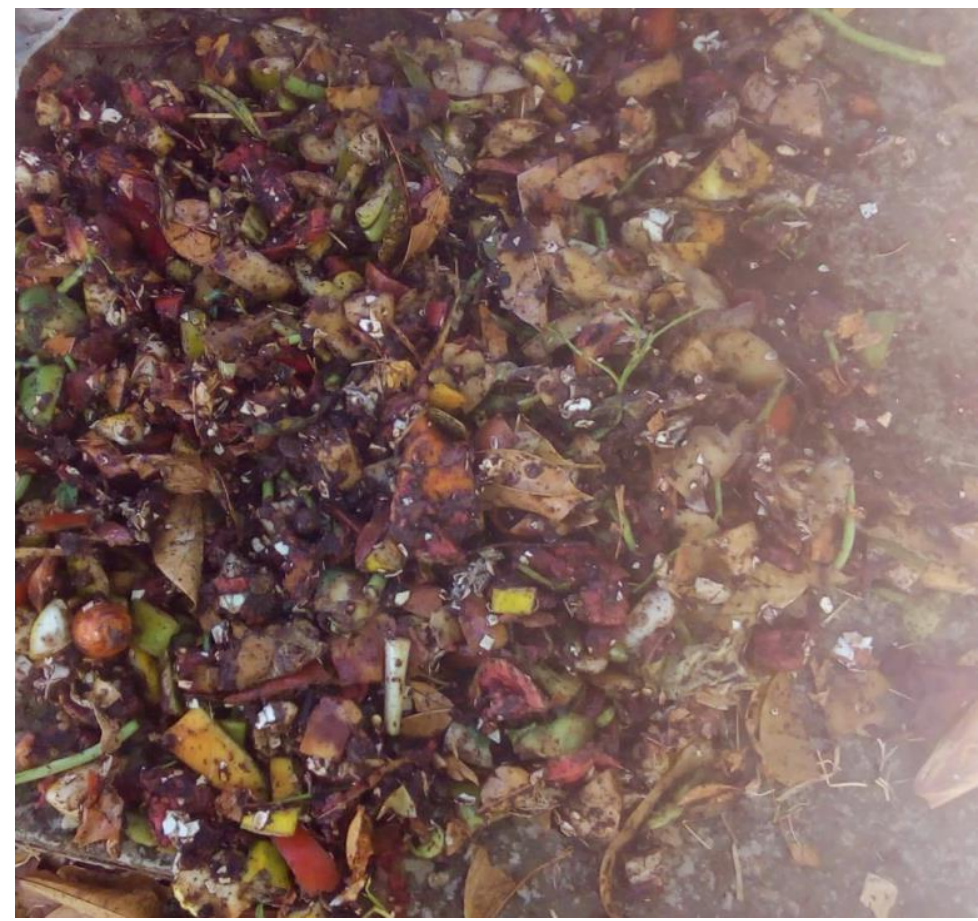

Fonte: dos autores (2019).

$3^{\circ}$ momento: Construção das composteiras, na área escolar arborizada, para isso foi necessário: 120 garrafas pet, 2 metros de tela, 60 unidades de ligas, matérias orgânicos, 30 litros de areia, 20 litros de serragem, 30 litros de terra, minhocas, tesouras e fitas adesivas.

FIGURA 2 - Construções das composteiras.

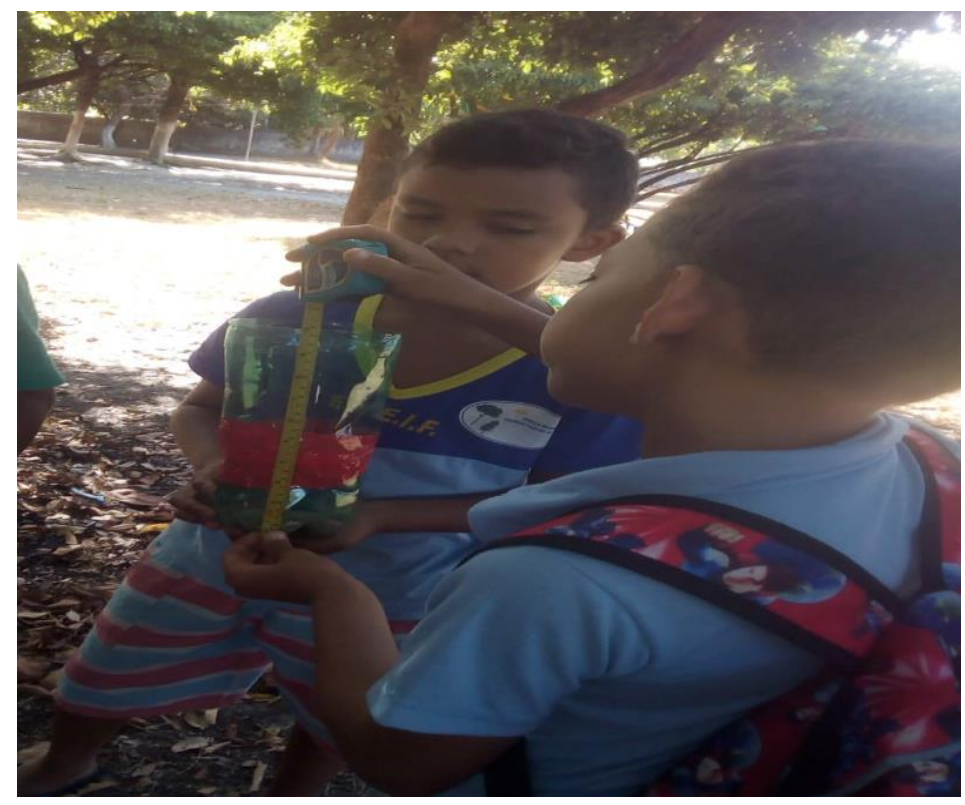

Fonte: dos autores (2019). 
FIGURA 3- Composteiras prontas pelos alunos.

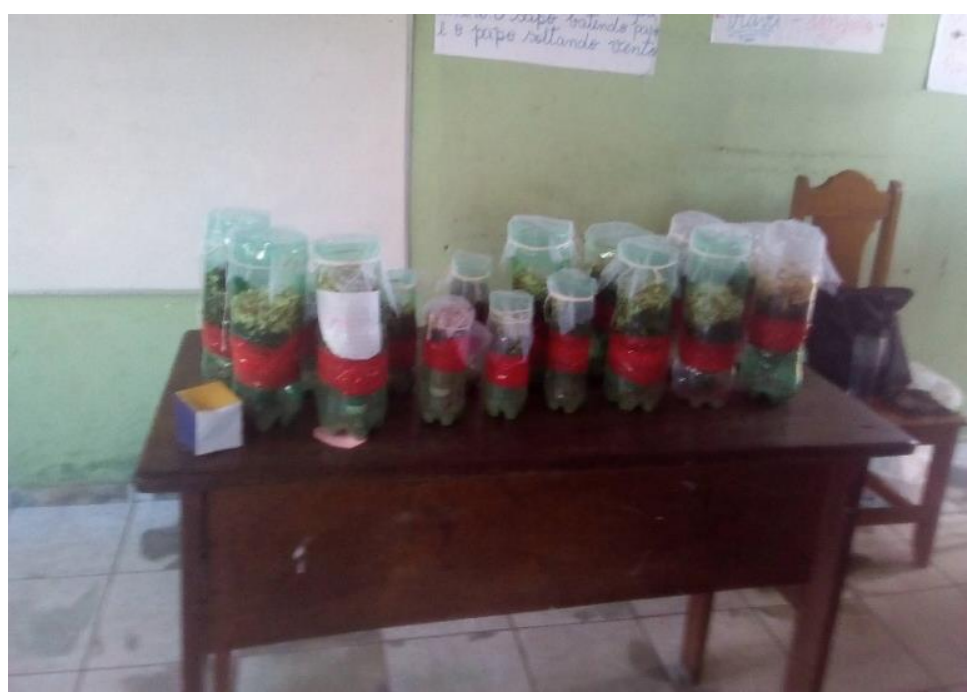

Fonte: dos autores (2019).

$4^{\text {o }}$ Momento: Após trinta dias os materiais das composteiras já estavam prontos para serem utilizados como adubo orgânico para a horta escolar, foi ressaltando nesse momento sobre a relevância da fertilidade do solo na vida de uma planta. Durante a explicação foram plantadas sementes de Petrolinum sativum popularmente conhecido como cheiro verde. Abaixo temos o adubo orgânico presente no solo da horta, mostrando o crescimento saudável das plantas.

FIGURA 4- Utilização do adubo orgânico na horta escolar.

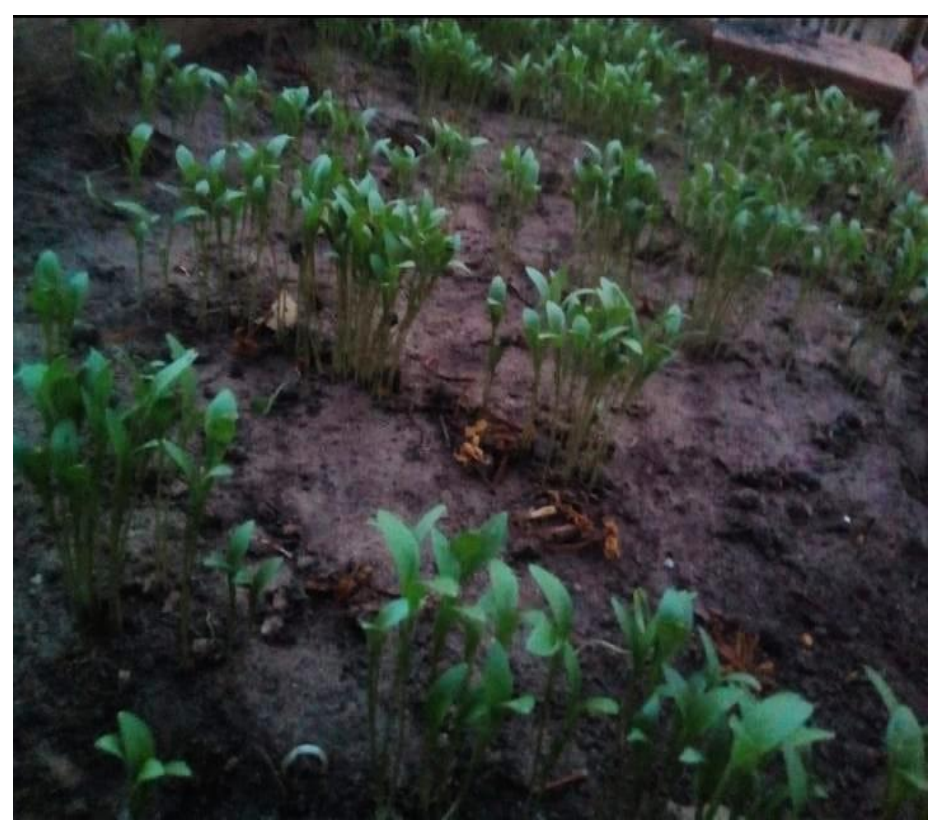

Fonte: dos autores (2019). 


\section{CONSIDERAÇÕES FINAIS}

Portanto, com a aplicação do projeto foi possível alcançar os objetivos propostos e contribuir para aprendizagem do alunado sobre a temática "o ensino das plantas e educação ambiental" e sua importância para o meio no qual estamos inseridos. Além disso, os alunos se sensibilizaram em relação ao desperdício de restos de alimentos e a importância das plantas para o meio ambiente sendo essências para o controle da temperatura da terra e entre outros motivos. Constatou-se que pode utilizar a compostagem como ferramenta de educação ambiental no processo de ensino/aprendizagem possibilitando a participação da comunidade escolar na práxi de educação ambiental.

\section{REFERÊNCIAS BIBLIOGRÁFICAS}

DIAS, G. F. Educação ambiental: princípios e práticas. 9. Ed. São Paulo: Gaia, 2004.

FERNANDES, R. S. et al. Como os jovens percebem as questões ambientais. Revista Aprender. 13 ed. a.3. jul./ago. 2003.

FONSECA, V. M. A educação ambiental na escola pública: entrelaçando saberes, unificando conteúdos. São Paulo: Biblioteca 24X7, 2009. 228p.

LIPAL, E. M. Educação ambiental nas escolas. Disponível emhttp://portal.mec.gov.br/dmdocu ments/publicação3.pdf acesso em 20/04/2010. Acesso em: 05 de setembro de 2019.

MASSUKADO, L. M. Desenvolvimento do processo de compostagem em unidade descentralizada e proposta de software livre para o gerenciamento municipal dos resíduos sólidos domiciliares. 2008. 182p. Tese (Doutorado). Escola de Engenharia de São Carlos, Universidade de São Paulo, São Carlos, 2008.

GUIMARÃES, C. F., NUNES, E. C., ROCHA, S. N., LIMA, S. F. O Ensino de Plantas e Educação Ambiental: Estratégias para o Ensino de Ciências na Amazônia. Complexitas - Rev. Fil. Tem. Belém, v. 4, n. 2, p. 43-49, jul./dec. 2019. Disponível em: http://www.periodicos.ufpa.br/index.php/complexitas/article/view/8166>. Acesso em: 30 de janeiro de 2020. 